\title{
ANNOUNCEMENT
}

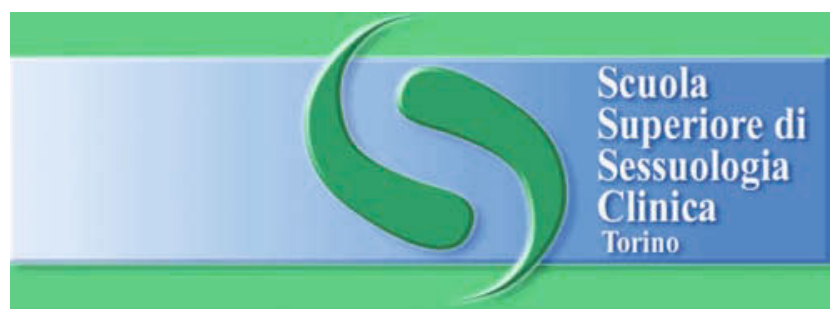

\section{Scientific Headmastership}

Prof. Giorgio Abraham

Professor of Psychiatry

University of Geneva
Prof. Dario Fontana

Professor of Urology

University of Turin

The Postgraduate School of Clinical Sexology (SSSC) (Turin - Italy)

Organizes two-year courses (200 h each) for first and second level of

\section{Sex Counselling}

Sex Counselling is not an autonomous professionalism but

a specific competence added and integrating one's own professionalism.

Several sexual deseases simply clear up by careful listening and right counselling.

A Counsellor has to acquire the ability to collaborate with different professional figures, integrating their own professionalism and specific knowledges.

Enrolments in courses will close in June 2008.

For information and registration (deadline June 2008) please contact:

Secretariat SSSC: Turin, C.so Unione Sovietica, 335

Tel./Fax 011. 6199465

segreteria@sssc.torino.it

www.sssc.torino.it 